\title{
THE IMPACT OF EARLY SEASON INSECTICIDES IN AN INTEGRATED FRUIT PRODUCTION PROGRAMME ON APPLE
}

\author{
P.W. SHAW ${ }^{1}$, S.J. BRADLEY ${ }^{2}$ and J.T.S. WALKER ${ }^{2}$ \\ The Horticulture and Food Research Institute of New Zealand Ltd., \\ ${ }^{1}$ Nelson Research Centre, P O Box 220, Motueka \\ ${ }^{2}$ Hawke's Bay Research Centre, Private Bag 1401, Havelock North
}

\begin{abstract}
Spring insecticide treatments were evaluated in a developmental Integrated Fruit Production programme for apples in Nelson and Hawke's Bay during the 1996-97 season. Air-blast sprayer applications of mineral oil, or oil plus either buprofezin or chlorpyrifos at 'green-tip', were compared for effectiveness against homopteran pests and their impact on beneficial insects. In Nelson, plots of the cultivar 'Sturmer' were treated with either a second application of buprofezin at 'pink' or chlorpyrifos in late November because of severe mealybug infestation the previous season. All treatments except oil alone gave excellent mealybug control. Buprofezin treatments provided better control of Froggatt's apple leafhopper and had higher populations of beneficial insects than chlorpyrifos treated plots. Woolly apple aphid was present in the buprofezin plots but was contained by the parasite, Aphelinus mali.

Keywords: insecticides, integrated fruit production, beneficial insects, mealybug, Froggatt's apple leafhopper
\end{abstract}

\section{INTRODUCTION}

HortResearch and ENZA International have commenced development and implementation of an Integrated Fruit Production (IFP) programme for pipfruit to meet the requirements of the European export market (Batchelor et al. 1997). This programme requires that priority is given to biological control of pests and that pesticide use is based on pest monitoring procedures and treatment thresholds. The insecticide upon which the IFP programme has so far been based is tebufenozide, a selective insect growth regulator. Tebufenozide provides excellent control of leafroller and codling moth (Cydia pomonella) but does not control homopteran pests at the level provided by traditional organophosphate insecticide programmes (Walkeret al. 1991).

Mealybugs (Pseudococcusspp.) have infested significantly more fruit after the first two seasons of IFP programmes in HortResearch orchards in Hawke's Bay and Nelson (Walker unpubl. data). Traditionally, organophosphates such as chlorpyrifos have been used to control mealybugs, but problems with resistance (Charles et al. 1993) and their unsuitability for IFP means that alternative control methods are needed. The insect growth regulator buprofezin effectively controls organophosphate resistant mealybugs in Hawke's Bay (Walker et al. 1993), but its selectivity for beneficial species has not previously been considered as an integral part of our apple pest management programmes.

Control of homopteran pests is an important requirement in the development of an IFP pipfruit spray programme, as is the selectivity of insecticide treatments on beneficial insects. The aim of this study was to assess the efficacy of early season insecticide applications of buprofezin and chlorpyrifos for homopteran pests and to determine their impact on beneficial insects. The effect of these treatments was also determined on Aphelinus mali, a parasitoid of woolly apple aphid (WAA), Erisoma lanigerumand are described in Bradleyet al. (1997). This parasitoid has provided effective control of WAA in the Nelson IFP block (Shaw and Walker 1996).

\section{Insecticide treatments}

\section{METHODS}

Proc. 50th N.Z. Plant Protection Conf. 1997: 283-287 
At the Nelson site (Appleby Research Orchard), the 'Sturmer' and 'Granny Smith' cultivars comprising the 0.6 ha IFP block were each divided in half. Each half was treated with mineral oil (2\%) plus either buprofezin (Applaud 25W) 50g/100 litres or chlorpyrifos (Lorsban 40EC) $100 \mathrm{ml} / 100$ litres on 8 September 1996. Sprays were applied by air-blast sprayer at a water rate of 2000 litres/ha. Because there had been a high level of mealybug infested fruit (34\%) in the Sturmer block at the previous harvest, each half of this cultivar block received a second application of the chemicals previously applied. The second buprofezin was applied at the 'pink' stage on 27 September and chlorpyrifos (Lorsban 50W) 50g/100 litres on 26 November 1996.

At the Hawke's Bay orchard (Lawn Rd), 'Royal Gala', 'Gala' and 'Braeburn' cultivars in the IFP block were divided into three equal sized plots of $c a .0 .13$ ha. At Braeburn 'green-tip' (2 September 1996) each cultivar received either mineral oil alone, or mineral oil plus buprofezin, or chlorpyrifos at the rates described above.

\section{Insect monitoring and fruit assessment}

At both locations single white corflute sticky board traps $(18 \mathrm{~cm}$ x $19 \mathrm{~cm})$ were hung from a tree $2 \mathrm{~m}$ above the ground in the centre of each plot. Counts of Froggatt's apple leafhopper (FALH) (Edwardsiana crataegi), predaceous mirid bugs and brown lacewings (Micromus tasmaniae) caught on the traps were recorded weekly between October and mid April. These were changed every three weeks or more often if required. One 'Pherocon' San José scale (Quadraspidiotus perniciosus) pheromone trap (13 cm x 8 $\mathrm{cm}$ ) was also hung in the same tree in each plot to monitor male scale flight activity. Scale traps were examined with a binocular microscope and the numbers of any male scale insects and, in Nelson, scale parasitoids were also recorded. Scale pheromone caps were changed every six weeks in Nelson and once at the end of January (between generations) in Hawke's Bay. At harvest, 2000 fruit comprising 100 fruit randomly picked from each of 20 trees were assessed per plot. Homopteran infestation of fruit was recorded.

A large plot size was required for monitoring populations of beneficial insects. The plots were replicated using two and three cultivar blocks in Nelson and Hawke's Bay respectively. Although in Nelson, the Sturmer block received two applications compared to the single application in Granny Smith, the cultivars were regarded as replicates of either buprofezin treated or chlorpyrifos treated plots for analysis. For the sticky board trap data, individual weekly trap-catches were used as a factor in analysis. Data from scale traps were analysed using total trap catch over the period divided by the number of weeks traps were operated.

\section{Insect monitoring}

\section{RESULTS}

Few FALH were trapped between October and January 1997 but catches increased in all treatments between February and mid-April (Table 1). Buprofezin treated plots had significantly fewer FALH than the corresponding chlorpyrifos treatments (Table 1), although in Hawke's Bay, neither insecticide treatment differed significantly from the oil alone treatment.

In Nelson the predator, Sejanus albisignata was the most commonly caught mirid species throughout the season, with most occurring in the buprofezin treated plots (Table 1). In Hawke's Bay, Romna scotti was the most common mirid species during spring and early summer, with $S$. albisignata becoming more common in the latter part of the season. There was no apparent effect from these spring applied pesticides on either mirid species in Hawke's Bay (Table 1).

Brown lacewings were more common earlier in the season (October-January) and coincided with peaks in the aphid complex infesting rapidly expanding shoots. In Hawke's Bay most lacewings were caught in the oil alone treatment, with similar numbers in both insecticide treatments. In Nelson there were significantly fewer lacewings in the chlorpyrifos treated plots between October and early January (Table 1).

TABLE 1: Mean number of Froggatt's apple leafhopper (FALH), predatory mirids and adult brown lacewings caught per sticky board trap per week for each insecticide treatment. 
FALH Predatory mirids Brown lacewings Treatment Oct-Jan Feb-Apr Oct-Jan Feb-Apr Oct-Jan Feb-Apr

Nelson

oil + buprofezin treated oil + chlorpyrifos treated

$\begin{array}{cccccc}0.03 & 2.80 & 1.17 & 1.73 & 0.89 & 0.37 \\ 0.83 & 20.94 & 0.13 & 0.23 & 0.16 & 0.27 \\ (0.226) & (3.950) & (0.198) & (0.327) & (0.204) & (0.266)\end{array}$

\section{Hawke's Bay}

\begin{tabular}{lcccccc} 
oil & 1.12 & 13.49 & 0.17 & 0.31 & 1.72 & 0.28 \\
oil + buprofezin & 0.78 & 9.13 & 0.68 & 0.05 & 0.60 & 0.22 \\
oil+ chlorpyrifos & 1.79 & 16.56 & 0 & 0.05 & 0.92 & 0.03 \\
S.E. & $(0.265)$ & $(1.912)$ & $(0.323)$ & $(0.094)$ & $(0.357)$ & $(0.119)$ \\
\hline
\end{tabular}

Seasonal catches of male San José scale in Nelson and Hawke's Bay and the scale parasitoid,Encarsia perniciosi, recorded in scale pheromone traps from Nelson only, are shown in Table 2. The number of male scale insects trapped in all plots was low during the first period of male scale flight activity (Oct-Jan) but increased greatly between February and April. Catches of E. perniciosi also increased in late summer and their abundance was related to male scale numbers trapped in the respective treatments.

TABLE 2: Mean weekly catches of San José scale males and Encarsia perniciosi from scale pheromone traps.

\begin{tabular}{lcccc}
\hline & \multicolumn{2}{c}{ San José scale } & \multicolumn{2}{c}{ Encarsia perniciosi } \\
Treatment & Oct-Jan & Feb-Apr & Oct-Jan & Feb-Apr \\
\hline $\begin{array}{l}\text { Nelson } \\
\text { oil + buprofezin treated }\end{array}$ & 0.88 & 8.63 & 1.38 & 2.73 \\
oil + chlorpyrifos treated & 0.21 & 5.32 & 0.19 & 1.78 \\
S.E. & $(0.106)$ & $(1.649)$ & $(0.312)$ & $(0.624)$ \\
Hawke's Bay & & & & \\
oil & 0 & 1.41 & - & - \\
oil + buprofezin & 0.04 & 1.01 & - & - \\
oil+chlorpyrifos & 0.02 & 1.34 & - & - \\
S.E. & $(0.020)$ & $(0.537)$ & & \\
\hline
\end{tabular}

\section{Harvest assessment}

In Hawke's Bay Gala strains, the addition of buprofezin and chlorpyrifos to oil appeared to reduce the mean percentage of fruit infested by mealybug compared with oil alone (Table 3). Mealybug fruit infestation at harvest showed little difference between the chlorpyrifos and buprofezin treatments in any cultivars (Table 3). Mealybug infested fruit in the Nelson Sturmer and Granny Smith treatments was reduced toca. 3\% and ca. $1 \%$ from $34 \%$ and $7 \%$ respectively in the previous season. Variation in the level of greedy scale (Hemiberlesia rapax) fruit infestation between the two Nelson cultivars (Table 3 ) was probably due to the plots' proximity to neighbouring host vegetation, rather than effects from spring insecticides. Scale infested fruit increased from $0.6 \%$ to $4.1 \%$ from the previous season in the Sturmers, and $0.2 \%$ to $1.9 \%$ in the Granny Smith, despite the addition of spring insecticides into the programme.

TABLE 3: Mean percentage of fruit infested with homopteran pests at harvest.

\begin{tabular}{|c|c|c|c|}
\hline Mealybug & $\begin{array}{c}\text { San José } \\
\text { scale }\end{array}$ & $\begin{array}{l}\text { Greedy } \\
\text { scale }\end{array}$ & $\begin{array}{c}\text { Woolly } \\
\text { apple aphid }\end{array}$ \\
\hline
\end{tabular}

\section{Nelson}




\section{Sturmer Pippin}

oil + buprofezin, buprofezin

oil + chlorpyrifos, chlorpyrifos

Granny Smith

oil + buprofezin

oil + chlorpyrifos

\section{Hawke's Bay \\ Gala Strains}

oil

oil + buprofezin

oil + chlorpyrifos

S.E.

\section{Braeburn}

oil

oil + buprofezin

oil + chlorpyrifos

\subsection{0}

3.60

1.05

1.35

1.50

1.05

2.85

1.95
1.10

2.20

0.25

0.15

1.10

0.15

0.35

0.15

$\begin{array}{cccc}1.27 & 0.03 & 0 & 0.57 \\ 0.42 & 0 & 0.03 & 0.05 \\ 0.41 & 0 & 0 & 0.12 \\ (0.026) & (0.014) & (0.014) & (0.010)\end{array}$

$\begin{array}{cccc}0.10 & 0 & 0.05 & 0.50 \\ 0 & 0 & 0.05 & 1.54 \\ 0.10 & 0 & 0.05 & 0.04\end{array}$

In Nelson less than $0.3 \%$ of fruit were infested by WAA, compared with $1.5 \%$ and $0.9 \%$ for Sturmer and Granny Smith respectively in the previous season. In Hawke's Bay, WAA infested fruit was below $2 \%$, which was greatly reduced from the previous season ( $12 \%$ and $64 \%$ for Gala and Braeburn respectively).

\section{DISCUSSION}

The early season treatments of either buprofezin or chlorpyrifos, in combination with mineral oil at 'green tip', provided excellent control of mealybug at harvest. The single application of either chemical in the Granny Smith plots reduced the 1996 infestation level and provided effective and similar levels of control. Second applications of both buprofezin or chlorpyrifos in the more heavily infested Sturmer plots, reduced mealybug fruit infestation at harvest by $85-90 \%$ compared to the previous season.

None of the treatments provided season long control of scale insects which probably infested the plots in mid and late-summer from shelter trees nearby. Fruit infestation was higher than in 1996 and either mid-season insecticide treatment, or replacement of shelter with non-host species, may be required to provide adequate control in future. The scale parasitoid, E. perniciosi was present throughout the block and its abundance in each plot appeared to be related to scale density rather than to any treatment effect.

In Nelson, one or two chlorpyrifos sprays suppressed predatory mirid populations all season. A similar effect on mirid populations was observed for the first part of the season in Hawke's Bay. It is difficult to ascertain whether this is a direct effect on mirids from the chlorpyrifos or any subsequent effect on their prey.

A. maliwere rare in chlorpyrifos treated plots all season (Bradley et al. 1997), which reflected their respective WAA populations. Despite differences in bothA. mali activity and WAA populations between the two treatments in Nelson, there was no difference in the level of WAA infested fruit, which was at lower levels than the previous season. This was probably due to biological control by A. maliin buprofezin plus oil and oil alone plots, and by a combination of chemical and biological control in the chlorpyrifos plus oil plots. This season's results confirms that effective biological control of WAA can be achieved by A. mali (Shaw and Walker 1996). In Hawke's Bay, the differences in WAA infested fruit that occurred (Table 3) may have been due to biological control being disrupted by subsequent insecticide treatments in some plots.

Monitoring of FALH with sticky traps detected differences between the treatment blocks. Buprofezin has been shown to provide control of FALH nymphs in a laboratory bioassay (Charles 1996), but control with pre-flowering applications in the field has not been reported previously. Results from this study suggest that buprofezin is effective against FALH and that a single application at 'green tip' may provide adequate season- 
long suppression of this pest. In Hawke's Bay, where all treatments were applied at the earlier Braeburn 'green-tip' timing (September 2), the effect on FALH was less apparent than with the later timing in Nelson (September 8 and 27 on Sturmer). Clearly the closer to flowering the buprofezin application is made, the greater the effectiveness of this treatment against neonate FALH nymphs emerging from overwintering eggs.

Results from this trial suggest that one or two pre-flowering applications of buprofezin can provide similar levels of mealybug control and better suppression of FALH than the equivalent number of early season chlorpyrifos sprays. Buprofezin is an important pesticide in an IFP pipfruit programme as it is more selective than chlorpyrifos to beneficial insects such as S. albisignata and A. mali. The potential problem with immigration of scale into orchards in mid to late summer indicates the need to investigate alternative products with similar levels of selectivity.

\section{ACKNOWLEDGEMENTS}

We are grateful for technical assistance provided by Roger Wallis and Vanessa Murrell. This research was supported by funding from ENZA New Zealand(International) and the Foundation for Research Science and Technology.

\section{REFERENCES}

Batchelor, T.A., Walker, J.T.S. and Manktelow, D.W.L., 1997. New Zealand integrated fruit production for pipfruit - charting a new course. Proc. 50th N.Z. Plant Prot. Conf.: (this volume).

Bradley, S.J., Murrell, V.C., Shaw, P.W. and Walker, J.T.S., 1997. Effect of orchard pesticides on Aphelinus mali, the woolly apple aphid parasitoid. Proc. 50th N.Z. Plant Prot. Conf: ( this volume).

Charles, J.G., Walker, J.T.S. and White, V., 1993. Resistance to chlorpyrifos in the mealybugs Pseudococcus affinis and P. longispinus in Hawkes Bay and Waikato pipfruit orchards. Proc. 46th N.Z. Plant Prot. Conf: 120-125.

Charles, J.G., 1996. Can buprofezin control Froggatt's apple leafhopper,Edwardsiana crataegi? Proc. 49th N.Z. Plant Prot. Conf: 81-84.

Shaw, P.W. and Walker, J.T.S., 1996. Biological control of woolly apple aphid by Aphelinus mali in an integrated fruit production programme in Nelson. Proc. 49th N.Z. Plant Prot. Conf: 59-63.

Walker, J.T.S., Baynon, G.T. and White, V., 1991. Insect control on apples with RH5992, a novel insect growth regulator.Proc. 44th N.Z. Weed and Pest Control Conf: 66-69.

Walker, J.T.S., White, W. and Charles, J.G., 1993. Field control of chlorpyrifos-resistant mealybugs (Pseudococcus affinis) in a Hawke's Bay orchard.Proc. 46th N.Z. Plant Prot. Conf: 126-128. 